\title{
Lagarta-do-cartucho na produção de milho: Avaliação de métodos de controle
}

\section{Fall armyworm in corn production: Evaluation of control methods}

\author{
Sander Martinho Adams \\ Universidade Federal de Santa Maria \\ E-mail: sander.adams@hotmail.com \\ OrcID: https://orcid.org/0000-0003-4895-8237
}

John Lenon Klein

Universidade Federal de Santa Maria

E-mail: johnlenonklein@yahoo.com.br

OrclD: https://orcid.org/0000-0001-8337-4152

Alexandra Fabielle Pereira Viana

Universidade Federal de Santa Maria

E-mail: alexandra viana@hotmail.com

OrcID: https://orcid.org/0000-0002-6757-7360

Patricia Machado Martini

Universidade Federal de Santa Maria

E-mail: patriciammartini@hotmail.com

OrcID: https://orcid.org/0000-0002-0648-4064

Leonel da Silva Rodrigues

Universidade Federal de Santa Maria

E-mail:rodrigues_leonel@hotmail.com

OrcID: https://orcid.org/0000-0002-9272-9151

Dari Celestino Alves Filho

Universidade Federal de Santa Maria

E-mail: darialvesfilho@hotmail.com

OrclD: https://orcid.org/0000-0003-2559-7504

Ivan Luiz Brondani

Universidade Federal de Santa Maria

E-mail: ivanbrondani@gmail.com

OrclD: https://orcid.org/0000-0002-6526-3042

Resumo: Considerando as grandes perdas produtivas causadas pela lagarta-do-cartucho na cultura do milho, objetivou-se avaliar o emprego de métodos de controle isolados ou associados no combate dessa praga. $O$ delineamento experimental foi de blocos ao acaso foi adotado em esquema fatorial $2 \times 3$ (tecnologia na cultivar e controle adicional, respectivamente) em quatro repetições, compondo os tratamentos: milho transgênico (controles adicionais: agente químico, agente biológico e sem controle adicional) e milho convencional (controles adicionais: agente químico, agente biológico e sem controle adicional). O milho BT foi mais produtivo quando não houve controle adicional e quando este foi biológico. $O$ milho convencional submetido ao controle químico teve maior produção quando comparado ao controle biológico. O milho BT foi eficiente no controle da lagarta-do-cartucho e o controle químico considerado o método adicional mais eficiente para o milho convencional.

Palavras-chave: Bacillus thuringiensis. Controle biológico. Escore de danos visuais. Spodoptera frugiperda.

Abstract: Considering the large productive losses caused by the caterpillar in the corn crop, the objective was to evaluate the use of isolated or associated control methods to combat this pest. The experimental design was a randomized block in a $2 \times 3$ factorial scheme (technology in the cultivar and additional control, 
respectively) in four replications, composing the treatments: transgenic corn (additional controls: chemical agent, biological agent and without additional control) and conventional corn (additional controls: chemical agent, biological agent and without additional control). BT corn was more productive when did not additional control and when it was biological. Conventional corn submitted to chemical control had higher production when compared to biological control. BT corn was efficient in controlling the caterpillar and the chemical control considered the most efficient additional method for conventional corn.

Keywords: Bacillus thuringiensis. Biological control. Visual scale of damage. Spodoptera frugiperda.

Data de recebimento: 09/07/2018

Data de aprovação: 11/09/2020

DOI: https://doi.org/10.30612/agrarian.v14i51.8408

\section{Introdução}

Dentre as culturas de grãos, o milho é uma das mais importantes do mundo (Moraes, Lourenção, Paterniani, 2015). Segundo Duarte, Mattoso e Garcia (2017), seu uso está muito difundido nas cadeias produtivas da alimentação humana e animal além de ser importante componente da indústria de transformação. No Brasil, considerando primeira, segunda e terceira safras, na temporada 2019/20, essa cultura deve ocupar uma área de 18,5 milhões hectares, com expectativa de colheita recorde de 101 milhões de toneladas (Conab, 2020).

Em diversas regiões brasileiras é possível obter mais de uma safra de milho por ano. É possível identificar uma grande intensificação na produção deste cereal os últimos anos. No período compreendido de 1986 a 2017, a produção de milho no país cresceu 146,87\%, enquanto a área cultivada cresceu apenas 14,36\% (Duarte et al., 2017). Como ponto negativo, a intensificação da produção, favorece a ocorrência de pragas e insetos que geram prejuízos econômicos em função da redução de produtividade (Scoton et al., 2020).

Dentre os insetos que atacam a cultura do milho, a lagarta-do-cartucho (Spodoptera frugiperda lepidoptera: Noctuidae) é a praga mais importante (Silva et al., 2020). Essa lagarta pode atacar desde as plântulas após a emergência até os grãos da espiga em formação, mas possui como característica principal se alojar e consumir as folhas do cartucho (Toscano, Gonzatto, Cardoso, Maruyama, 2010). Cruz et al. (2012) relataram que as perdas na produção podem chegar a $60 \%$, de acordo com genótipo, estádio de desenvolvimento e época de cultivo da planta.

A utilização de milho geneticamente modificado, que expressa as toxinas Cry ou Vip (milho BT) que possuem ação inseticida, tem sido a principal estratégia de controle dessa praga (Farias et al., 2014). Contudo, existem relatos de populações de lagartas que são resistentes a essa tecnologia, o que exige do produtor tomar a difícil decisão de optar por outros métodos de controle, de forma individual ou associadas. $\mathrm{O}$ controle químico costuma ser empregado através da pulverização de produtos com amplo espectro, e dessa forma, combate inclusive os inimigos naturais de $S$. frugiperda existentes. Seu uso de modo equivocado, também pode causar problemas ambientais e de saúde humana além de selecionar populações de lagartas resistentes (Jesus, Boiça, Alves, Zanuncio, 2014).

O controle biológico surge como alternativa ao problema ambiental atribuído aos métodos de controle químico por serem mais específicos ao controle das pragas alvo. Contudo, existem vários métodos de controle biológico, com grande variação de eficiência ou com esta ainda não determinada. Assim, o objetivo desse trabalho foi avaliar métodos de controle da lagarta do cartucho de forma individual ou associados na cultura do milho.

\section{Material e Métodos}

O experimento foi conduzido no Laboratório de Bovinocultura de Corte, do Departamento de Zootecnia da Universidade Federal de Santa Maria, localizado no município de Santa Maria, na região fisiográfica da Depressão Central do estado do Rio Grande do Sul, situado a 95 metros de altitude, com latitude $29^{\circ} 43^{\prime}$ sul e longitude $53^{\circ} 42^{\prime}$ oeste, o solo da área experimental pertence a unidade de mapeamento São Pedro, classificado como ARGISSOLO VERMELHO DISTRÓFICO Arênico (Streck et al., 2008). O clima da região é 
subtropical de verão úmido e quente, conforme classificação de Köppen (Alvares, 2013). Os dados climatológicos históricos e do período estão demonstrados na Tabela 1.

Tabela 1. Dados climáticos do período experimental e históricos.

\begin{tabular}{|c|c|c|c|c|c|}
\hline \multirow{2}{*}{ Variáveis } & Dezembro & Janeiro & Fevereiro & Março & Abril \\
\hline & \multicolumn{5}{|c|}{ Período experimental } \\
\hline Precipitação, (mm) & 324,3 & 175,1 & 84,3 & 132,4 & 129,8 \\
\hline$N^{\circ}$ de precipitações $(>1 \mathrm{~mm})$ & 10 & 15 & 5 & 6 & 6 \\
\hline Temperatura, $\left({ }^{\circ} \mathrm{C}\right)$ & 24,07 & 25,09 & 24,38 & 23,14 & 19,71 \\
\hline Insolação total, (horas) & 211,0 & 212,4 & 217,7 & 209,5 & 207,2 \\
\hline \multicolumn{6}{|c|}{ Média histórica (1961 -1990) } \\
\hline Precipitação, (mm) & 142,2 & 163,0 & 127,2 & 136,2 & 121,4 \\
\hline $\mathrm{N}^{\circ}$ de precipitações $(>1 \mathrm{~mm})$ & 8 & 9 & 8 & 8 & 6 \\
\hline Temperatura, $\left({ }^{\circ} \mathrm{C}\right)$ & 23,3 & 24,2 & 23,9 & 21,9 & 18,4 \\
\hline Insolação total, (horas) & 244,7 & 225,2 & 196,7 & 184,9 & 168,7 \\
\hline
\end{tabular}

Fonte: Dados da Rede do Instituto Nacional de Meteorologia (INMET), obtidos em agosto de 2017.

A área experimental foi composta por 24 parcelas com $54 \mathrm{~m}^{2}$ de área cada, e foram divididas em quatro blocos. As avaliações, foram realizadas em $22,5 \mathrm{~m}^{2}$ centrais de cada parcela. $\mathrm{O}$ híbrido de milho BT AS 1551 PRO 2 e sua isolinha convencional (híbrido com a mesma carga genética, mas que não contém o gene BT) foi utilizado para compor os seguintes tratamentos:

-Milho transgênico sem controle adicional;

-Milho transgênico com controle adicional via agente químico do grupo dos piretróides na dosagem de $120 \mathrm{ml} \mathrm{ha}^{-1}$ (12 g l.A ha-1).

-Milho transgênico com controle adicional via agente biológico Bacillus thuringiensis na dosagem de $400 \mathrm{~g} \mathrm{ha}^{-1}\left(12,8\right.$ I.A ha $\left.{ }^{-1}\right)$.

-Milho convencional sem controle adicional;

-Milho convencional com controle adicional via agente químico do grupo dos piretróides na dosagem de $120 \mathrm{ml} \mathrm{ha}^{-1}$ (12 g I.A ha-1).

-Milho convencional com controle adicional via agente biológico Bacillus thuringiensis na dosagem de $400 \mathrm{~g} \mathrm{ha}^{-1}\left(12,8\right.$ I.A ha- $\left.{ }^{-1}\right)$.

A cultura antecessora (Lolium multiflorum) foi dessecada com glifosato (3 I/ha- $\left.{ }^{-1}-1440 \mathrm{~g} \mathrm{I.A/ha-1}\right)$. O preparo convencional do solo foi realizado com uso de subsolador para descompactação, e nivelamento com grade leve. A semeadura foi realizada em 15/12, através de semeadora tracionada a trator com espaçamento de $75 \mathrm{~cm}$ entre linhas, com deposito de 4,5 sementes por metro linear, o que resultou na densidade de 60.000 plantas por hectare.

Conforme análise do solo, a área experimental apresenta as seguintes características: pH em água $(1: 1)=4,8$; índice SMP = 5,7; Matéria orgânica $(M O)=2,0 \%$; Fósforo $\left(\mathrm{P}_{2} \mathrm{O}_{5}\right)=19,9 \mathrm{mg} / \mathrm{dm}^{-3}\left(\right.$ Mehlich $\left.{ }^{-1}\right)$ e Potássio $\left(\mathrm{K}_{2} \mathrm{O}\right)=52 \mathrm{mg} / \mathrm{dm}^{-3}$. A adubação foi calculada de acordo com as recomendações de Marino et al. (2004) visando à produção de sete toneladas de grãos por hectare. A adubação de base foi realizada no momento da semeadura correspondeu a $450 \mathrm{~kg} / \mathrm{ha}$ de NPK na fórmula 05-20-20. Após a emergência das plantas, realizou-se a ressemeadura ou o desbaste das plantas para adequar a densidade pré-estipulada. Foi necessária também a aplicação de herbicida para controle de plantas daninhas, com aplicação do herbicida seletivo Atrazina (7,5 I/ha, dissolvidos em $300 \mathrm{l} / \mathrm{ha}$ de calda). A adubação de cobertura (nitrogenada) foi de $273 \mathrm{~kg} / \mathrm{ha}$, aplicados na forma de ureia $(46 \% \mathrm{~N})$, e dividida em duas aplicações iguais no estágio vegetativo, sendo a primeira quando as plantas estavam com quatro folhas e a segunda com sete folhas completamente expandidas (Sangoi et al., 2011).

As parcelas passaram a ser monitoradas quando se tornou possível identificar o ataque de lagartas. $O$ monitoramento foi realizado em 10 plantas aleatórias em cada parcela em intervalos de 3 dias, e seguiu a escala proposta por Davis e Williams (1992), onde as notas para o dano nas folhas causados pela lagarta do cartucho variam de 0 a 9 , sendo a menor nota para plantas sem danos e a maior nota para plantas completamente destruídas. Quando alguma parcela de um tratamento apresentava nota média igual ou superior a três, executava-se a intervenção de acordo com o tratamento proposto. As aplicações foram feitas através de pulverizador costal. Quando não foram mais possíveis intervenções devido à altura das plantas, as 
avaliações visuais foram realizadas em intervalos de cinco dias, com o objetivo de acompanhar a evolução dos danos.

A colheita foi realizada quando as plantas apresentaram teor de massa seca em torno de $66 \%$. As características morfométricas foram avaliadas após o corte a $20 \mathrm{~cm}$ do solo de 18 plantas de milho, equivalente a quatro metros lineares da parcela. A altura da planta e a altura da inserção da espiga foram mensuradas, considerando a área do corte como o ponto inicial, com o auxílio de uma fita métrica. O diâmetro do colmo foi mensurado através de paquímetro digital, na altura de corte da planta.

Realizou-se a separação dos componentes estruturais das plantas de cada parcela, para posterior secagem em estufa de ar forçado a $55^{\circ} \mathrm{C}$ durante 72 horas para a estimativa de produção de massa parcialmente seca (MPS). O delineamento experimental empregado foi o de blocos ao acaso em esquema fatorial de $02 \times 03$ (tecnologia da cultivar X controle adicional), com quatro repetições. Os dados coletados foram submetidos a teste de normalidade dos erros, através do teste de Shapiro-Wilk com posterior análise de variância. Em seguida, as médias foram comparadas pelo teste de Tukey, a $5 \%$ de significância. As análises estatísticas foram realizadas com auxílio do programa estatístico SISVAR 5.1 (Ferreira, 2011).

\section{Resultados e Discussão}

Conforme observado na Tabela 2, o milho BT sempre apresentou escore médio de danos visuais inferior ao convencional e necessitou apenas uma aplicação de controle adicional, enquanto que o convencional recebeu dez aplicações.

Tabela 2. Escore de médio de danos visuais e aplicações por data de avaliação.

\begin{tabular}{|c|c|c|c|c|c|c|c|c|c|c|c|c|c|c|c|c|}
\hline & & 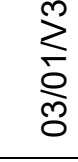 & $\underset{\substack{0 \\
0}}{+}$ & 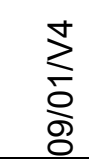 & 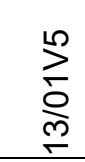 & $\frac{10}{\stackrel{2}{0}}$ & $\begin{array}{l}\stackrel{0}{2} \\
\stackrel{2}{\frac{0}{2}} \\
\frac{2}{r}\end{array}$ & 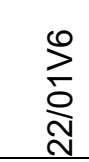 & 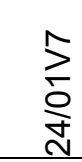 & $\begin{array}{l}\infty \\
\stackrel{\infty}{o} \\
0\end{array}$ & ঐ̊ & 离 & $\begin{array}{l}\stackrel{ }{2} \\
\text { } \\
\infty \\
0\end{array}$ & 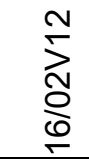 & 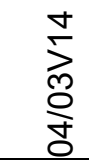 & $\underset{\stackrel{\nabla}{\perp}}{\stackrel{\nabla}{\circ}}$ \\
\hline \multirow{3}{*}{ C } & $S$ & 2,5 & 2,3 & 2,7 & 3,3 & 3,6 & 4,1 & 3,9 & 4,6 & 4,3 & 3,9 & 4,3 & 3,4 & 4,4 & 4,9 & 5,3 \\
\hline & $Q$ & 3,3 & 2,2 & 2,5 & 1,9 & 2,0 & 2,4 & 3,9 & 3,9 & 3,9 & 3,7 & 4,1 & 4,3 & 5,0 & 5,2 & 5,4 \\
\hline & B & 2,2 & 1,9 & 2,5 & 2,8 & 3,3 & 3,5 & 3,9 & 4,6 & 4,4 & 3,8 & 3,9 & 3,9 & 5,0 & 5,0 & 5,1 \\
\hline \multirow{3}{*}{1} & $S$ & 1,5 & 1,2 & 1,2 & 1,2 & 1,4 & 1,0 & 2,3 & 2,6 & 1,4 & 1,6 & 1,3 & 0,8 & 1,3 & 1,4 & 1,3 \\
\hline & $\mathrm{Q}$ & 1,7 & 1,1 & 1,3 & 0,8 & 0,8 & 1,2 & 2,3 & 2,7 & 2,0 & 1,4 & 1,8 & 1,0 & 2,3 & 2,5 & 2,1 \\
\hline & B & 1,8 & 1,0 & 1,1 & 1,2 & 1,5 & 1,4 & 1,6 & 1,8 & 1,4 & 1,1 & 1,0 & 0,6 & 1,3 & 1,3 & 1,6 \\
\hline
\end{tabular}

$\mathrm{C}=$ Convencional; $\mathrm{T}=$ Transgênico; $\mathrm{S}=$ Sem Controle; $\mathrm{Q}=$ Controle Químico; $\mathrm{B}=$ Controle Biológico e valores em negrito= Aplicação.

Foram realizadas quatro aplicações para o milho convencional submetido ao controle adicional químico e seis aplicações para o biológico. Efetuar o controle da lagarta no começo do ciclo permite a recuperação da área foliar da planta (Ota et al., 2011) contudo, no presente estudo a infestação se manteve durante todo período experimental. No dia 11/02/20 as plantas já estavam no estádio V9 e foi realizado o último controle adicional, devido ao porte elevado das plantas, o que dificultava a aplicação e reduzia sua eficiência. O método de aplicação, é um fator de extrema relevância na aplicação de inseticidas, uma vez que deverá garantir a deposição do produto onde a lagarta se encontra, ou seja, no interior do cartucho do milho, e de forma eficiente, evitando perdas para o ambiente (Jesus et al., 2014).

Do estágio V9 ao V12, o escore de danos nos métodos de controles químico e biológico passou de 3,9 e 3,7 no controle químico e biológico, respectivamente, para 5,0, o que representa crescimento de $28 \%$ nos danos perceptíveis nas folhas em apenas 14 dias. Este resultado comprova a rápida capacidade da lagarta em causar danos na cultura. Segundo Scoton et al. (2020), a intensificação nos danos da lagarta pode ser influenciada, entre outros fatores, pelas condições ambientais e estágio fisiológico da lagarta.

No momento que cessaram as aplicações (Tabela 3), houve ataque mais intenso da lagarta-docartucho no milho convencional. Esse resultado reforça. Apesar do ataque mais intenso, o escore de danos médio foi inferior ao encontrado por Ota et al. (2011) avaliando a tolerância do milho à lagarta-do-cartucho em diferentes ambientes. 
Tabela 3. Escore médio de danos causados pela lagarta do cartucho em híbridos de milho convencional ou transgênico durante o controle adicional (até estádio V9) e após controle adicional (após estádio V9).

\begin{tabular}{cccc}
\hline Cultivar & Controle Adicional & Até V9 & Após V9 \\
\hline \multirow{3}{*}{ Convencional } & Sem Controle & 3,5 & 4,4 \\
& Químico & 2,9 & 4,8 \\
& Biológico & 3,2 & 4,3 \\
\hline \multirow{3}{*}{ Transgênico } & Sem Controle & 1,5 & 1,1 \\
& Químico & 1,5 & 1,9 \\
& Biológico & 1,3 & 1,0 \\
\hline
\end{tabular}

Conforme exposto na Tabela 4, para a variável produção de grãos, houve diferença entre cultivares e métodos de controle adicional. O milho BT apresentou produção superior ao convencional quando não houve controle adicional $(7797,3$ vs $7226,7 \mathrm{~kg} / \mathrm{ha} 70 \% \mathrm{MS})$ e quando este foi biológico $(8076,7 \mathrm{vs} 7129,1 \mathrm{~kg} / \mathrm{ha} 70 \%$ MS), o que pode ser justificado pela maior resistência ao ataque da lagarta-do-cartucho. Dessa forma, o milho transgênico produziu bem com ou sem controle adicional.

Tabela 4. Produção (kg/ha 70\% MS); peso de 100 Grãos $(\mathrm{g})$ e características da espiga de híbridos de milho convencional ou transgênico submetidos a diferentes métodos de controle adicional da lagarta-docartucho.

\begin{tabular}{|c|c|c|c|c|c|c|}
\hline \multirow[b]{2}{*}{ Variáveis } & \multirow[b]{2}{*}{ Cultivar } & \multicolumn{3}{|c|}{ Controle adicional } & \multirow[b]{2}{*}{$\mathrm{P}$} & \multirow[b]{2}{*}{$\mathrm{CV}(\%)^{1}$} \\
\hline & & Sem Controle & $\begin{array}{l}\text { Controle } \\
\text { Químico }\end{array}$ & $\begin{array}{l}\text { Controle } \\
\text { Biológico }\end{array}$ & & \\
\hline $\begin{array}{l}\text { Produção } \\
\text { (kg/ha 70\%MS) }\end{array}$ & $\begin{array}{l}\text { Convencional } \\
\text { Transgênica } \\
\mathrm{P}\end{array}$ & $\begin{array}{l}7178,3^{\mathrm{Bab}} \\
7797,3^{\mathrm{A}} \\
0,0458 \\
\end{array}$ & $\begin{array}{l}7883,2^{a} \\
7786,7 \\
0,7343 \\
\end{array}$ & $\begin{array}{l}7129,1^{\mathrm{Bb}} \\
8076,7^{\mathrm{A}} \\
0,0052 \\
\end{array}$ & $\begin{array}{c}0,0313 \\
0,5110\end{array}$ & 14 \\
\hline $\begin{array}{l}\text { P100 grãos } \\
\text { (g) }\end{array}$ & $\begin{array}{l}\text { Convencional } \\
\text { Transgênica } \\
\mathrm{P}\end{array}$ & $\begin{array}{l}45,7^{\mathrm{Aa}} \\
42,2^{\mathrm{B}} \\
0,0089\end{array}$ & $\begin{array}{l}42,0^{\mathrm{b}} \\
41,3 \\
0,5441\end{array}$ & $\begin{array}{l}43,2^{\mathrm{ab}} \\
42,3 \\
0,4315\end{array}$ & $\begin{array}{l}0,0169 \\
0,5963\end{array}$ & 3,74 \\
\hline $\begin{array}{l}\text { Diâmetro espiga } \\
(\mathrm{mm})\end{array}$ & $\begin{array}{l}\text { Convencional } \\
\text { Transgênica } \\
\mathrm{P}\end{array}$ & $\begin{array}{l}49,5 \\
48,7 \\
0,2791 \\
\end{array}$ & $\begin{array}{l}49,4 \\
48,5 \\
0,2291 \\
\end{array}$ & $\begin{array}{l}49,6 \\
49,3 \\
0,7003 \\
\end{array}$ & $\begin{array}{l}0,9767 \\
0,5581\end{array}$ & 2,04 \\
\hline $\begin{array}{l}\text { Comprimento } \\
\text { espiga }(\mathrm{cm})\end{array}$ & $\begin{array}{l}\text { Convencional } \\
\text { Transgênica } \\
\mathrm{P}\end{array}$ & $\begin{array}{l}14,5^{\mathrm{Bb}} \\
15,6^{\mathrm{A}} \\
0,0089\end{array}$ & $\begin{array}{l}15,5^{\mathrm{a}} \\
15,5 \\
0,8674\end{array}$ & $\begin{array}{l}14,8^{\mathrm{Bab}} \\
15,6^{\mathrm{A}} \\
0,0484\end{array}$ & $\begin{array}{l}0,1707 \\
0.4774\end{array}$ & 3,40 \\
\hline
\end{tabular}

Valores seguidos por letra minúscula distinta na mesma linha diferiram entre si quanto ao controle adicional pelo teste de Tukey a $5 \%$ de probabilidade. Valores seguidos por letra maiúscula distinta na mesma coluna diferiram entre si quanto a cultivar pelo teste de Tukey a $5 \%$ de probabilidade. ${ }^{1} \mathrm{CV}$ - Coeficiente de variação.

O controle químico pode ser considerado o método mais eficiente para controle adicional da lagartado-cartucho, uma vez que não houve diferença entre o milho transgênico e convencional nesse método de controle $(7883,2$ vs $7786,7 \mathrm{~kg} / \mathrm{ha} 70 \% \mathrm{MS})$. Os coeficientes de variação (CV \%) das variáveis são indicativos da boa precisão do experimento. Conforme Scapim, Carvalho e Cruz (1985), que identificaram os limites de valores para classificação de precisão dos experimentos com milho, todas as características avaliadas no presente estudo tiveram CVs baixos.

Para a variável peso de 100 grãos, não houve diferença para o método de controle adicional no milho BT. Segundo Carvalho, Borsato, Cruz e Viana (2001), maior massa para 100 grãos é importante, uma vez que após o número de espigas é o fator que mais contribui na produção por planta. Contudo, para o milho convencional, o tratamento sem controle adicional apresentou valor superior $(45,7 \mathrm{~g})$ em comparação com o controle químico (42 g), e o controle biológico mostrou-se semelhante aos dois (43,2 g). Comparando os dados quanto a transgênico ou convencional, houve diferença apenas quando não houve controle adicional e o milho convencional foi superior $(45,7$ vs $42,2 \mathrm{~g})$.

O milho convencional sem controle adicional (com produção inferior e mais atacado pela lagarta) apresentou maior peso de 100 grãos. Segundo Melo et al. (2014), o canibalismo característico da lagarta do 
cartucho, que faz que os insetos se dispersem na planta, ocupando e causando danos também a espiga, assim, é possível que plantas desse tratamento possuíam menor número de grãos para nutrir por espiga e assim, estes ficaram maiores.

Não houve diferença no diâmetro da espiga entre os tratamentos. Já na característica comprimento da espiga, a cultivar BT foi superior a convencional no tratamento que não recebeu controle adicional bem como ao submetido ao controle biológico. Tal resultado deve estar associado aos danos causados pela lagarta do cartucho principalmente entre os estádios V5 até V12 (21/02/20) quando é determinado o tamanho da espiga (Bergamaschi \& Matzenauer, 2014).

Observando os resultados das Tabelas 3 e 4, percebe-se que as plantas de milho convencional submetidas com controle químico já estavam em V9 quando cessaram as aplicações e então passaram a receber maior ataque da lagarta. Assim, o desenvolvimento da espiga já estava num estágio avançado, diferentemente do tratamento milho convencional sem controle adicional ou o submetido ao controle biológico, que foram atacados logo após a emergência.

Os valores das variáveis altura da planta, altura da espiga e diâmetro do colmo, estão expressos na Tabela 5. Não houve diferença quanto a forma de controle adicional, mas sim entre as cultivares testadas. $O$ milho BT foi mais alto, o que deve estar associado a menores danos sofridos pelo ataque da lagarta do cartucho (Tabelas 2 e 3), resultando em maior crescimento apical através da emissão de novas folhas e, consequentemente, maior área para realização de fotossíntese.

A variável altura da espiga demonstrou o mesmo comportamento, o que pode ser justificado pela correlação de $52 \%$ entre essas duas variáveis (Faluba et al., 2010). Guadagnin et al. (2011) avaliaram a cultivar AS 1551 YG, em diferentes ambientes na safra 2010-2011 no RS encontraram valores semelhantes para altura da planta $(230 \mathrm{~cm})$ embora a altura da espiga $(124 \mathrm{~cm})$, fosse um pouco inferior, o que demonstra boa adaptação da cultivar na região central do estado.

Para diâmetro do colmo houve apenas diferença entre as cultivares quando o controle adicional foi biológico e o milho BT foi superior ao convencional. Segundo Fancelli e Dourado (2000), este componente além de sustentar folhas e inflorescências atua no armazenamento de sólidos solúveis que são posteriormente, utilizados na formação dos grãos. Dessa forma, plantas com maior diâmetro de colmo tendem a ser mais vigorosas e produtivas. Os resultados do presente trabalho concordam com os autores, uma vez que das plantas submetidas ao controle adicional biológico, o milho BT obteve-se produção superior ao convencional (8076,7 vs $7129,1 \mathrm{~kg} / \mathrm{ha}$, respectivamente).

Tabela 5. Diâmetro do Colmo, Altura da Planta e de inserção da espiga de híbridos de milho submetidos a diferentes métodos de controle da lagarta-do-cartucho.

\begin{tabular}{|c|c|c|c|c|c|c|}
\hline \multirow[b]{2}{*}{ Variáveis } & \multirow[b]{2}{*}{ Cultivar } & \multicolumn{3}{|c|}{ Controle adicional } & \multirow[b]{2}{*}{$\mathrm{CV}(\%)^{1}$} & \multirow[b]{2}{*}{$P$} \\
\hline & & $\begin{array}{c}\text { Sem } \\
\text { Controle }\end{array}$ & $\begin{array}{l}\text { Controle } \\
\text { Químico }\end{array}$ & $\begin{array}{c}\text { Controle } \\
\text { Biológico }\end{array}$ & & \\
\hline \multirow{3}{*}{ Altura Planta $(\mathrm{cm})$} & Convencional & $198,4^{\mathrm{B}}$ & $206,5^{B}$ & $198,4^{\mathrm{B}}$ & \multirow{3}{*}{3,78} & 0,2956 \\
\hline & Transgênica & $232,7^{\mathrm{A}}$ & $228,8^{A}$ & $229,9^{A}$ & & 0,7849 \\
\hline & $\mathrm{P}$ & 0,0001 & 0,0023 & 0,0001 & & \\
\hline \multirow{3}{*}{ Altura Espiga $(\mathrm{cm})$} & Convencional & $106,2^{B}$ & $111,6^{\mathrm{B}}$ & $105,6^{\mathrm{B}}$ & \multirow{3}{*}{3,92} & 0,1707 \\
\hline & Transgênica & $130,9^{A}$ & $129,6^{A}$ & $126,9^{A}$ & & 0,4774 \\
\hline & $\mathrm{P}$ & 0,0000 & 0,0001 & 0,0000 & & \\
\hline \multirow{3}{*}{$\begin{array}{l}\text { Diâmetro Colmo } \\
\qquad(\mathrm{mm})\end{array}$} & Convencional & 22,1 & 21,8 & $20,9^{\mathrm{B}}$ & \multirow{3}{*}{4,1} & 0,1981 \\
\hline & Transgênica & 22,8 & 22,8 & $22,6^{A}$ & & 0.9622 \\
\hline & $\mathrm{P}$ & 0,3194 & 0,1358 & 0,0197 & & \\
\hline
\end{tabular}

Valores seguidos por letra maiúscula distinta na mesma coluna diferiram entre si quanto a cultivar pelo teste de Tukey a $5 \%$ de probabilidade. ${ }^{1} \mathrm{CV}$ - Coeficiente de variação.

\section{Conclusões}

O combate a lagarta-do-cartucho por meio do milho BT ou controle químico foi eficiente e o emprego desses dois métodos associados dificulta a ocorrência de resistência.

$\mathrm{O}$ ataque da lagarta-do-cartucho é intensificado no milho convencional quando o método de controle é suspenso.

Mais estudos com Bacillus thuringiensis são necessários a fim de melhorar sua eficiência. 


\section{Agradecimentos}

Aos amigos e colegas do Laboratório de Bovinocultura de Corte da UFSM pela dedicação na condução e coleta de dados da pesquisa.

\section{Referências}

Alvares, C.A. (2013). Köppen's climate classification map for Brazil. Meteorologische Zeitschrift, 22(6), 711728. https://doi.org/10.1127/0941-2948/2013/0507

Bergamaschi, H., Matzenauer, R. (2014). O milho e o clima. Porto Alegre: Emater / RS - Ascar. 84.

Carvalho, C.G.P., Borsato, R., Cruz, C.D., Viana, J.M.S. (2001) Path analysis under multicollinearity in S0 x S0 maize hybrids. Crop Breeding and Applied Biotechnology, 1(3), 263-270. https://doi.org/10.13082/19847033.v01n03a06

Conab (Companhia Nacional De Abastecimento), (2020). Acompanhamento da safra brasileira Grãos. Brasília-DF. 7 - safra 2019/20 - 9.

Cruz, I., Figueiredo, M., Silva, R.B., Silva, I.F., Paula, C.S., Foster, J.E. (2012). Using sex pheromone traps in the decision-making process for pesticide application against fall armyworm (Spodoptera frugiperda (Smith) (Lepidoptera: Noctuidae)) larvae in maize. Pest Management Science, Hoboken, 58, 83-90. https://doi.org/10.1080/09670874.2012.655702

Davis, F.M., Ng,S.S., Williams, W.P. (1992). Visual rating scales for screening whorl-stage corn for resistance to fall armyworm. Mississippi: Agricultural and Forest Experiment Station, 186, 1-9.

Duarte, J.O., Mattoso, M.J., Garcia, J.C. (2017). Milho - Importância socioeconômica.

Faluba, J.S., Mirandai, G.V., Delima, R.O., Souza, L.V., Debem, E.C., Oliveira, A.M.C. (2010). Potencial genético da população de milho UFV 7 para o melhoramento em Minas Gerais. Ciência Rural, 40(6) 12501256. https://doi.org/10.1590/S0103-84782010000600002

Fancelli, A.L., Dourado Neto, D. (2000). Produção de milho. Guaíba: Agropecuária, 360.

Farias, J.R., Andow, D.A., Horikoshi, R.J., Sorgatto, R.J., Fresia, P., Santos, A.C., Omoto, C. (2014). Fieldevolved resistance to Cry1F maize by Spodoptera frugiperda (Lepidoptera: Noctuidae) in Brazil. Crop Protection, 64(2) 150-158. https://doi.org/10.1016/j.cropro.2014.06.019

Ferreira, D.F. (2011) Sisvar: a computers statistical analysis system. Ciência e Agro Tecnologia, 35, 10391042. https://doi.org/10.1590/S1413-70542011000600001

Guadagnin, J.P., Rodrigues, L.R., Filho, C.A., Losso, A., Emygdio, B.M., Ames, C.G., Buzzetti, D., Santos, F.M., Machado, J.R.A., Caraffa, M., Trentin, R. (2011). Avaliação de cultivares transgênicas de milho para indicação no estado do Rio Grande do Sul - safra 2010/2011. Pesquisa Agropecuária Gaúcha. 17(1), 79-84.

Jesus, F.G., Boiça Junior, A.L., Alves, G.C.S., Zanuncio, J.C. (2014). Behavior, development and predation of Podisus nigrispinus (Hemiptera: Pentatomidae) on Spodoptera frugiperda (Lepidoptera: Noctuidae) fed transgenic and conventional cotton cultivars. Annals of Entomological Society of American. 107, 601-606. https://doi.org/10.1603/AN13100

Marino, J.T., Gianello, C., Anghinoni, I., Bissani, C.A., Camargo, F.A.O., Wiethölter, S. (2004). Manual de adubação e de calagem para os estados do Rio Grande do Sul e de Santa Catarina / Sociedade Brasileira de Ciência do Solo. Comissão de Química e Fertilidade do Solo. 10 ed. - Porto Alegre, 400.

Moraes, A.R.A., Lourenção A.L., Paterniani, M.E.A.G.Z. (2015). Resistance of conventional and isogenic transgenic maize hybrids to Spodoptera frugiperda (Lepidoptera: Noctuidae). Bragantia, Campinas. 74(1), 5057. https://doi.org/10.1590/1678-4499.0367

Ota, E.C., Lourenção, A.L., Duarte, A.P., Ramos Junior, E.U., Ito, A.A. (2011). Tolerância do milho à lagartado-cartucho. Bragantia, Campinas. 70(4), 850-859. https://doi.org/10.1590/S0006-87052011000400018

Sangoi, L., Vargas, V.P., Schimitt, A., Pletsch, A.J., Vieira, J., Saldanha, A., Siega, E., Carniel, G., Mengarda, R.T., Picoli Junior, G.J. (2011). Disponibilidade de nitrogênio, sobrevivência e contribuição dos perfilhos ao 
rendimento de grãos do milho. Revista Brasileira de Ciência do Solo, 35, 183-191. https://doi.org/10.1590/S0100-06832011000100017

Scapim, C.A., Carvalho, C.G.P., Cruz, C.D. (1985). Uma proposta de classificação dos coeficientes de variação para a cultura do milho. Pesquisa Agropecuária Brasileira, Brasília, 30(5), 683-686.

Scoton, A.M.N., Degrande, P.E., Silva, M.B., Jacques, F.L., Lourenção, A.L.F., Souza, E.P. (2020). Spodoptera frugiperda (J. E. Smith, 1797) (Lepidoptera: Noctuidae) control and productive performance of BT maize genotypes. Brazilian Journal of Agriculture. 95(1), 68-82. https://doi.org/10.37856/bja.v95i1.4014

Silva, C.L.T., Paiva, L.A., Correa, F., Silva, F.C., Pelosi, A.P., Araujo, M.S., Almeida, A.C.S., Jesus, F.G. (2020) Interaction between corn genotypes with BT protein and management strategies for Spodoptera frugiperda (Lepidoptera: Noctuidae). Florida Entomologist, 102(4), 725-730. https://doi.org/10.1653/024.102.0409

Streck, E.V., Kämpf, N., Dalmolin, R.S.D., Klamt, E., Nascimento, P.C., Giasson, E., Pinto, L.F.S. (2008). Solos do Rio Grande do Sul. $2^{\mathrm{a}}$ ed. Porto Alegre, Emater/RS, 222.

Toscano, L.C., Gonzatto, F.A., Cardoso, A.M., Maruyama, W.A. (2010). Interação de híbridos de milho cultivados na safrinha e o controle químico da lagarta-do-cartucho Spodoptera frugiperda (J.E Smith, 1797). Agrarian, Dourados, 3(7), 24-33. 